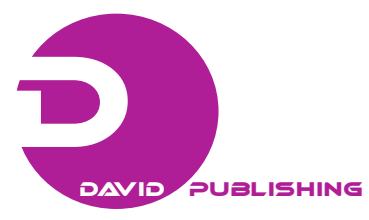

\title{
A Study for the Environmental Design Supporting an Intellectual Activity
}

\author{
Keisuke Aoyagi $^{1}$ and Akiko Watanabe ${ }^{2}$ \\ 1. Graduate School of Science and Technology for Future Life, Tokyo Denki University, Tokyo 120-8551, Japan \\ 2. Department of Architecture, Tokyo Denki University, Tokyo 120-8551, Japan
}

\begin{abstract}
Japan is facing a demographic challenge of a falling birthrate coupled with an aging society that is already adversely affecting the economy. The situation is only expected to worsen as the working-age population continues to decrease. Well aware of this situation, businesses and offices are seeking ways to enhance the intellectual productivity of their workers. This paper explores environmental elements of work spaces that might stimulate intellectual activity. Using a CAD (AutoCAD) miniature garden program, subjects were asked to design a project room that is optimized for creative work using a certain number of elements-11 types of walls, 14 types of floors, 4 types of scenery, 3 types of furniture and 3 types of plantings - but the subjects were free to position and arrange these elements any way they want. The subjects were then interviewed using the evaluation grid method. Based on the results, we created an evaluation structure diagram by analyzing key words and phrases emphasized by subjects in the interviews. The overall evaluation structure represents a summary overview of all 30 subjects who participated in the experiment. This approach captures all the key elements of the office environment that might be used to stimulate intellectual activity of employees.
\end{abstract}

Key words: Office environmental design, intellectual productivity, evaluation grid method CG (computer graphics) type miniature garden.

\section{Introduction}

Japan is in the midst of a demographic crisis [1] that is projected to reduce the working-age population of the country from 84.42 million in 2005 to 45.95 million by the year 2055. Improving the productivity of workers has thus emerged as an critical issue in order maintain the nation's economic status quo. Well aware of this situation, businesses and offices are seeking ways to boost the intellectual productivity of their workers.

The Intellectual Productivity Committee [2] has outlined three levels of activity in promoting intellectual productivity: information processing is the first level, followed by intellectual processing as the second level, and knowledge creation is the third level. Haneda et al. in a series of papers [3-8] examined

\footnotetext{
Corresponding author: Keisuke Aoyagi, graduate student, research field: architecture planning. E-mail: yagi.aoyagi@gmail.com.
}

intellectual productivity from an environmental engineering perspective, focusing on such factors as thermal environment, lighting, freeway noise and amount of ventilation. However, very few studies have looked at the third level-knowledge creation-from an architectural planning perspective, so that it is what we intend to do in this study. Clearly, creating an environment that supports and stimulates intellectual activity is essential for knowledge creation. In this paper, we will identify those environmental factors that stimulate intellectual activity and formulate guidelines for planning and designing office spaces that are conducive to intellectual productivity.

\section{Experimental Overview}

In this work, we conducted an experiment to derive environmental factors involved in promoting or stimulating intellectual activity by having the subjects themselves engage in the creative work of designing a 
project room using a CAD CG (computer graphics) program (Fig. 1). Fig. 2 shows an experimental scene. Taking awareness based on the CG of the designed office spaces as the original construct, we then employed the conventional evaluation grid method (which we define here as the miniature garden CG evaluation grid method) to interview the subjects and derived environmental factors in the form of words and phrases. The reason we adopted the evaluation grid method is that it offers the best way to draw out environmental factor evaluations from respondents having potential to stimulate intellectual activity that is otherwise difficult to access through ordinary interview responses to questions prepared in advance. If we can structurally clarify how the derived evaluation items are related through laddering, this should enable us to understand the involved elements. The reason we employ the miniature garden approach is that ordinary evaluation grid-based interviews are typically based on photographs which involve a number of disadvantages: one can only comprehend the scope of the image captured in the photograph, and one's impression of the interior space can be readily swayed by conditions shown in the photograph. By using the miniature garden approach, the subjects can obtain a good grasp of the overall space since they themselves configure the interior spaces using constituent parts that are prepared beforehand.

\subsection{Experimental Setup}

Thirty office workers were recruited as subjects for the experiment. The age and job distribution of the subjects are shown in Figs. 3-4. The subjects were asked to design the interior layout of an office space measuring 9,000 mm wide $\times$ 7,000 $\mathrm{mm}$ deep $\times 2,700$ mm high using a CAD program (Fig. 2). This is approximately the minimum required office space for a single worker [9]. In carrying out the assignment, the subjects were provided with certain environmental elements to work with: walls, floors, landscaping, furniture and plantings.

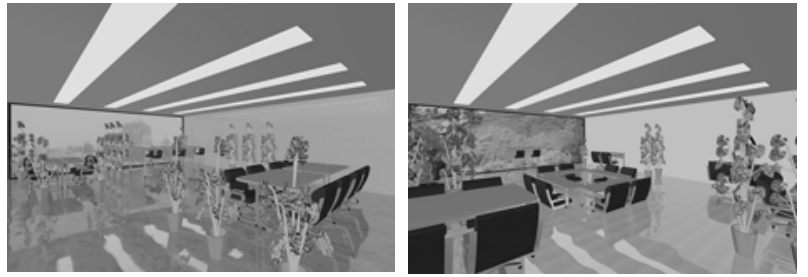

Fig. 1 CG was produced in the CAD.
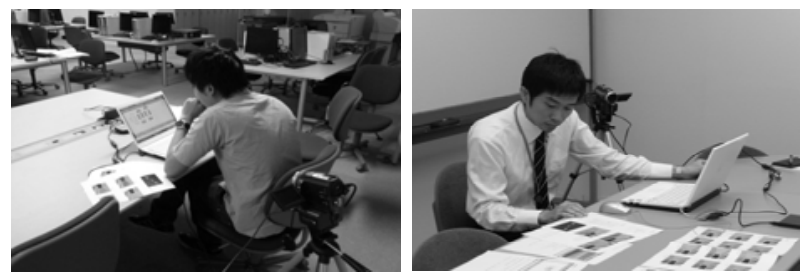

Fig. 2 State of the experiment.

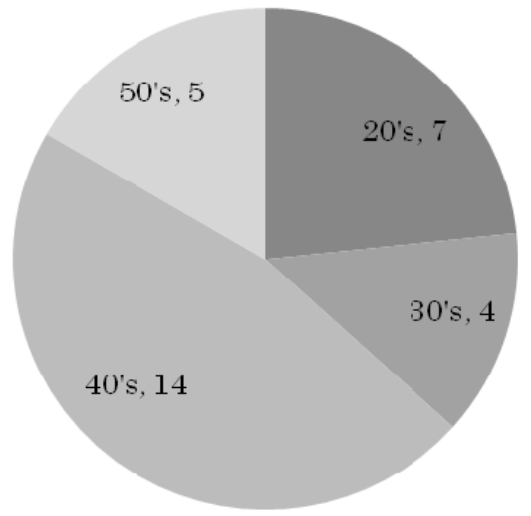

Fig. 3 Age structure.

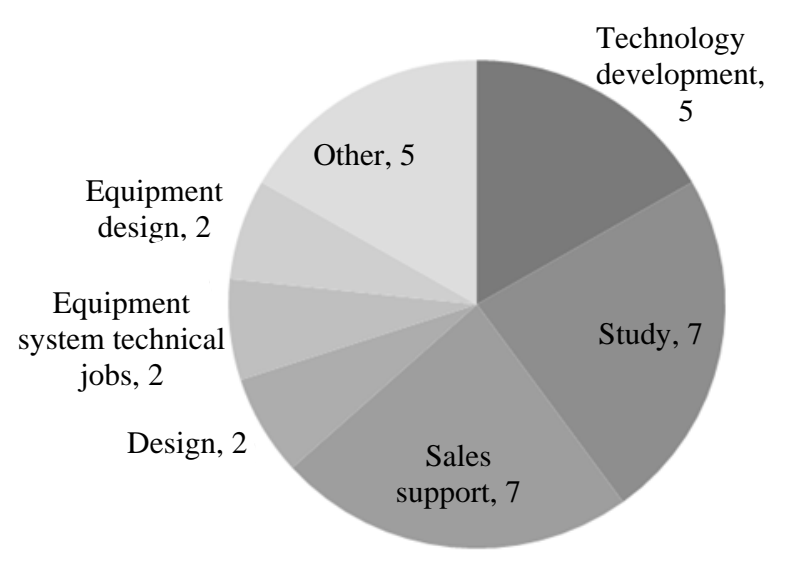

Fig. 4 Job structure.

\subsection{Experimental Procedure}

Subjects were instructed that they would engage in a creative work assignment to design the layout of a project room. Since the work involves the use of CAD, the subjects were first taught how to use the CAD 
program. They were provided with CAD instructions and a list of environmental elements available to use in the layout work. After explaining how the program worked, we gave the subjects a chance to practice and familiarize themselves with CAD operations. After the practice session, the CAD program was returned to start state in preparation for the actual experiment. The subjects were allowed 30 minutes to complete their office space designs, and were notified 10 minutes and 5 minutes before the time limit. We videoed the entire creation process. After the layout work was completed, the subjects took a short break while we setup to conduct the interviews (a questionnaire was used for working people to understand the effectiveness of CAD computer graphics). During the interviews, videos of the creation process, and computer graphics and birds-eye views of the office spaces created were employed as visual aids. Subjects were questioned using a laddering approach. When the subjects could not add anything more in response to a question, the interviewer went on to the next question. All the interviews were recorded for later analysis by a three-person panel. Table 1 shows a summary overview of the five-point scale questionnaire given to the office workers.

\section{Experimental Conclusions}

In order to gain an understanding of the tendency of evaluation structures for all the participants, we compiled an aggregate evaluation structure based on words and phrases extracted through analysis from all of the subjects (Fig. 5). Evaluation items expressed by subjects in their own words during the evaluation grid-based interviews were analyzed by a three-person panel in order to minimize the subjectivity of the researchers and reach generalized interpretations. Next, we aggregated the evaluation structures of the 30 participants into a single evaluation structure diagram, and examined the common evaluation items derived from two or more subjects to determine if they could best be classified as broader concepts, basic evaluation items, or subordinate concepts.

In the survey of workers, we found that the broader concept evaluation items, shared and derived for more than 15 (more than half) of the subjects, were "improve communication (16/30)", "relaxing (15/30)", and “settled down (15/30)" (Fig. 6). No basic evaluation items-items shared and derived for 10 or fewer participants-were detected (Fig. 7). Two subordinate concept evaluation items were shared and derived for 15, or half of the participants: "bench style seating (15/30)" and "planting (15/30)” (Fig. 8). In terms of correlations between elements, we found a strong correlation between "improve communication" and "conducive to conversation” (Fig. 9).

\section{Considerations}

\subsection{Considerations: Experiment}

First we considered whether the characteristics of the study population were really captured by the miniature garden evaluation grid method. The basic evaluation items for the workers were wide-ranging, and as we have observed, no shared items were derived for the aggregated evaluation structure diagram. This can be attributed to the richness of

\section{Table 1 Questionnaire.}

\begin{tabular}{ll}
\hline Q1. Operation of the CAD \\
\hline 1 & Ease of operation \\
\hline 2 & Understanding of the operation \\
\hline Q2. CG of the CAD \\
\hline 1 & The difference between the actual space \\
2 & Sense of distance of space in CG \\
3 & Image of how you have their space \\
\hline Q3. Miniature garden techniques using CAD \\
\hline 1 & Type of wall \\
2 & Type of floor \\
3 & Types of furniture \\
4 & Type of landscape \\
5 & Type of planting \\
6 & Use of design to the actual \\
7 & Did you make the space as the image \\
\hline
\end{tabular}




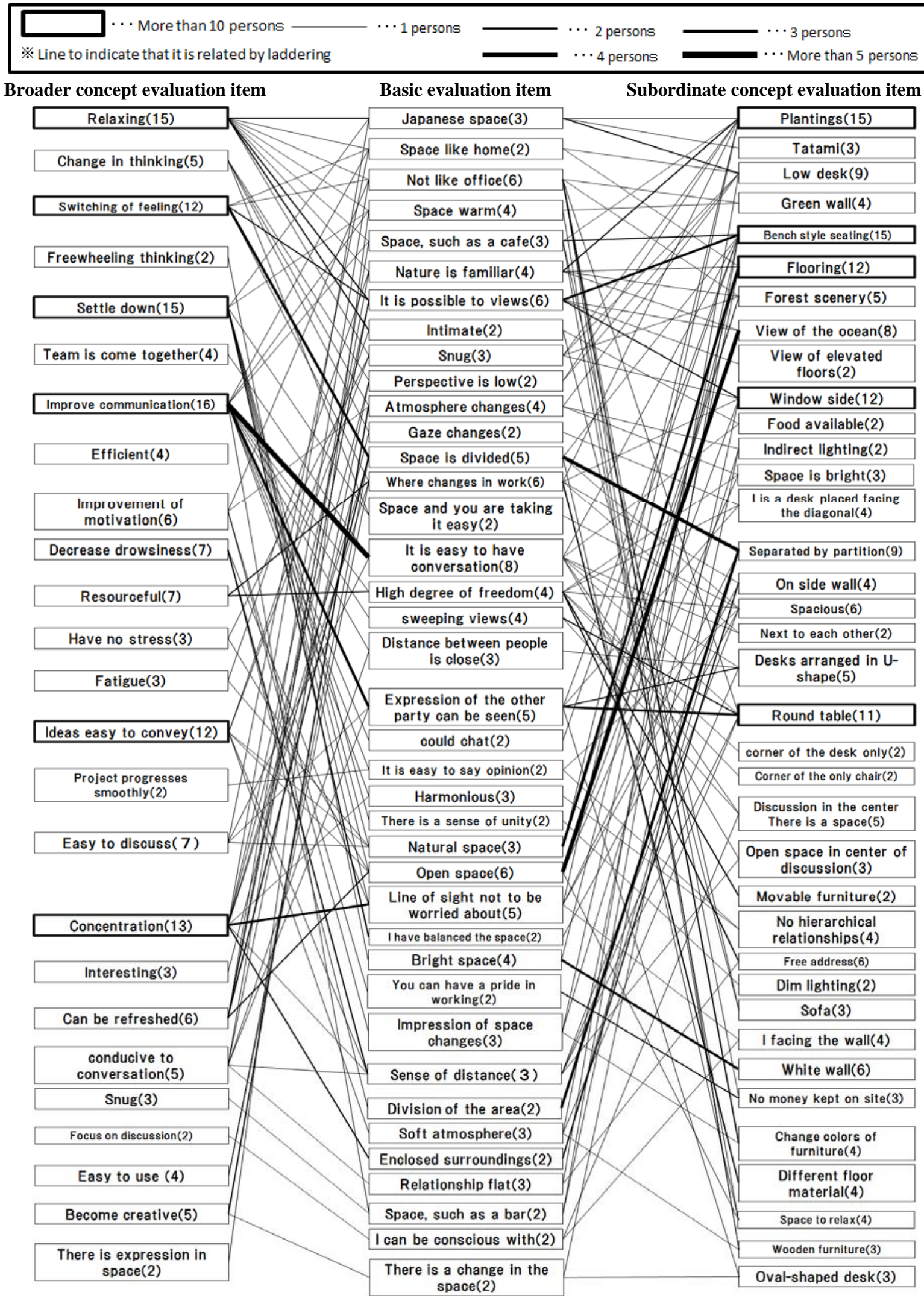

Fig. 5 Evaluation structure diagram of the whole. 


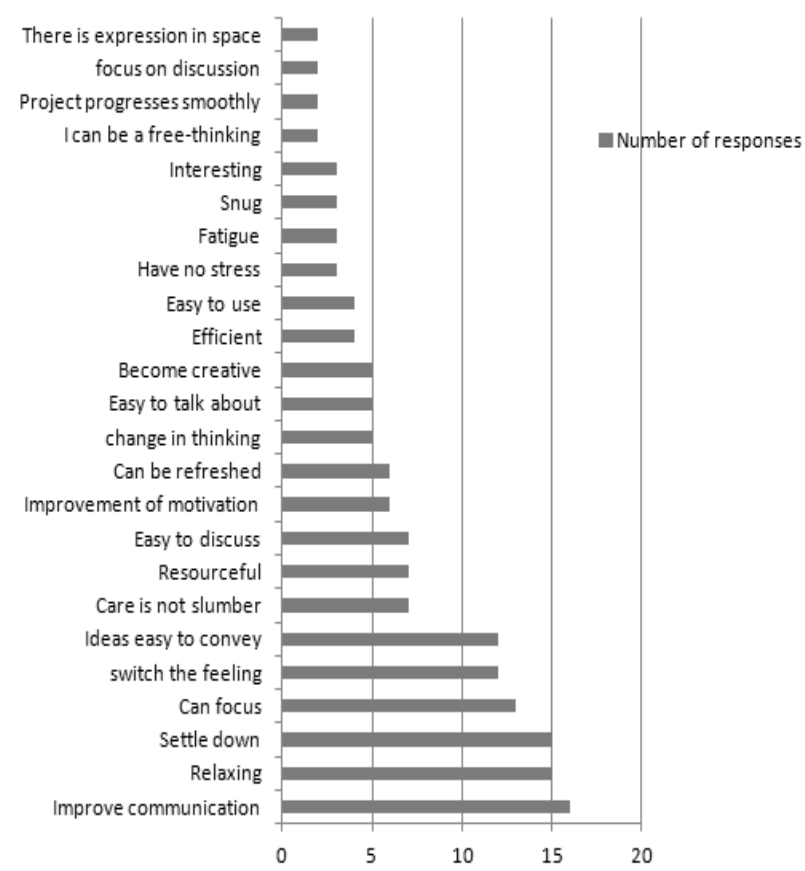

Fig. 6 Broader concept evaluation item.

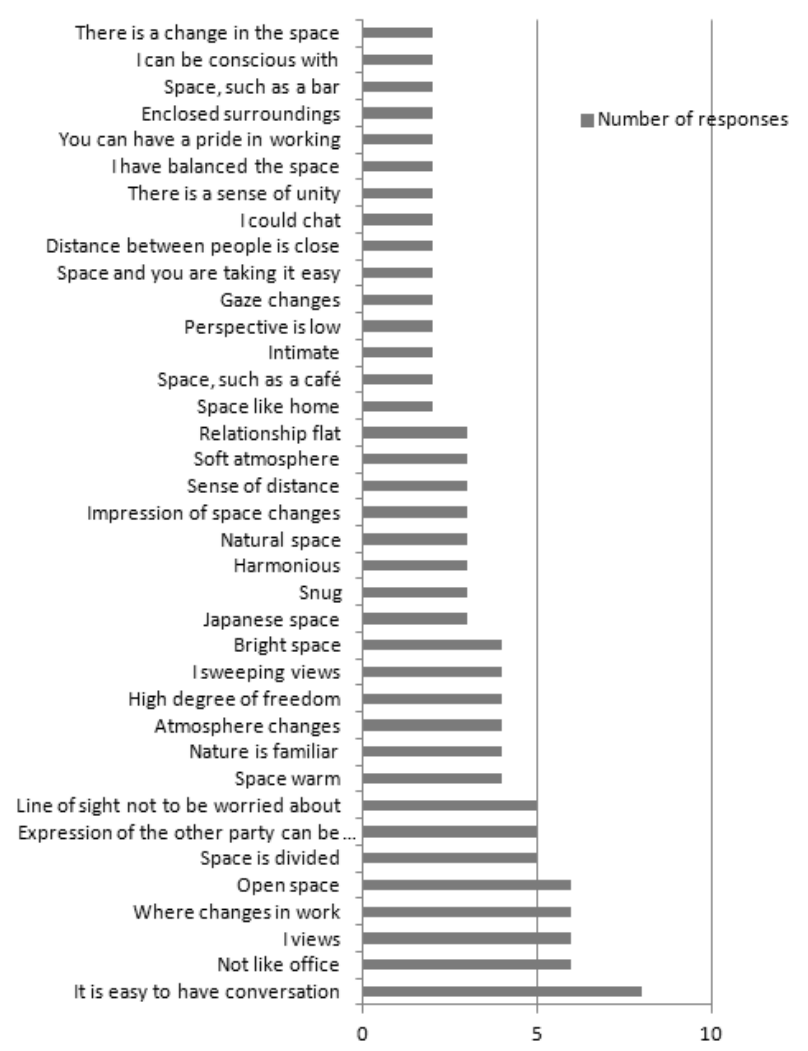

Fig. 7 Basic evaluation item.

vocabulary for describing office environments, and the diverse ways of looking at office environments based on work experience in different workplaces. In

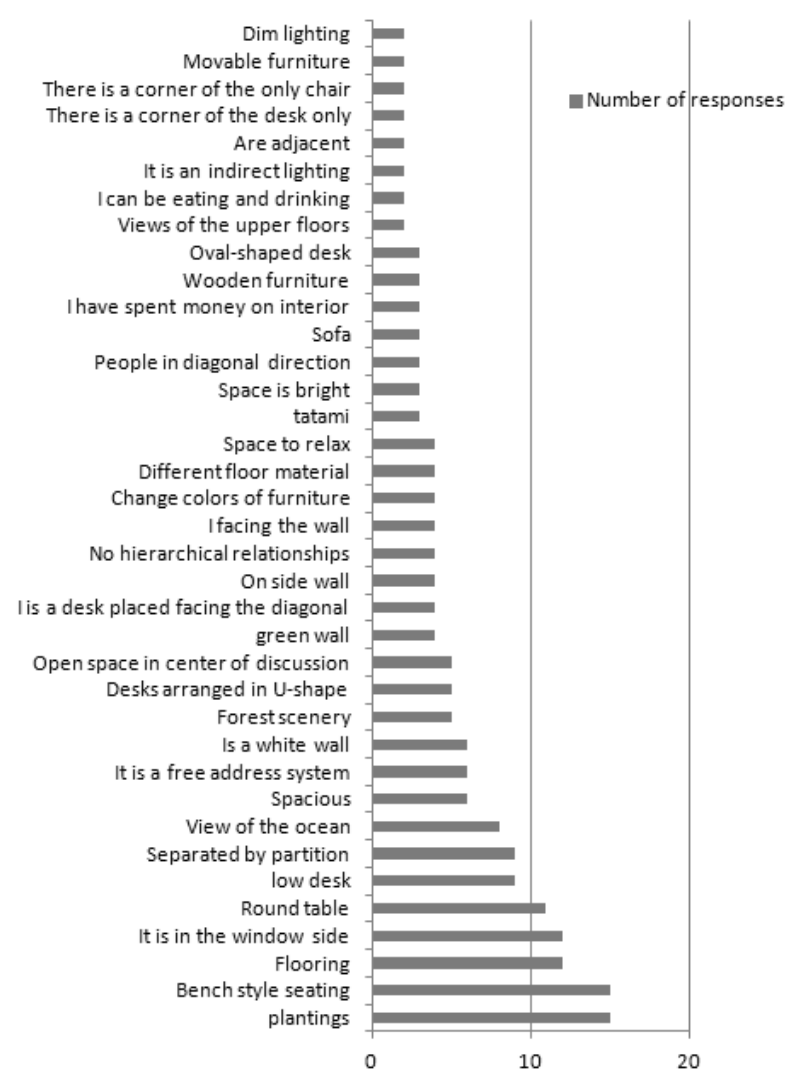

Fig. 8 Subordinate concept evaluation item.

addition, the following shared factors were derived: relaxing, improve communication, settled down, plantings and countertop tables. This suggests that when seeking a place to do creative work, one would look for a place that is relaxing and comfortable, a place that promotes communication and has plantings and countertop tables, a place that is conducive to conversation, yet also a place that promotes intellectual activity.

\subsection{Considerations: Miniature Garden Approach}

Inui et al. [10] conducted a study assessing the comfort of office environments by having subjects create an evaluation structure through pair wise comparison of photographs with elements of an congenial office environment where they themselves would like to work. Among the basic environmental assessment items they derived through this procedure were bright atmosphere, relaxing and peaceful, comfortable and conducive to concentration. By 


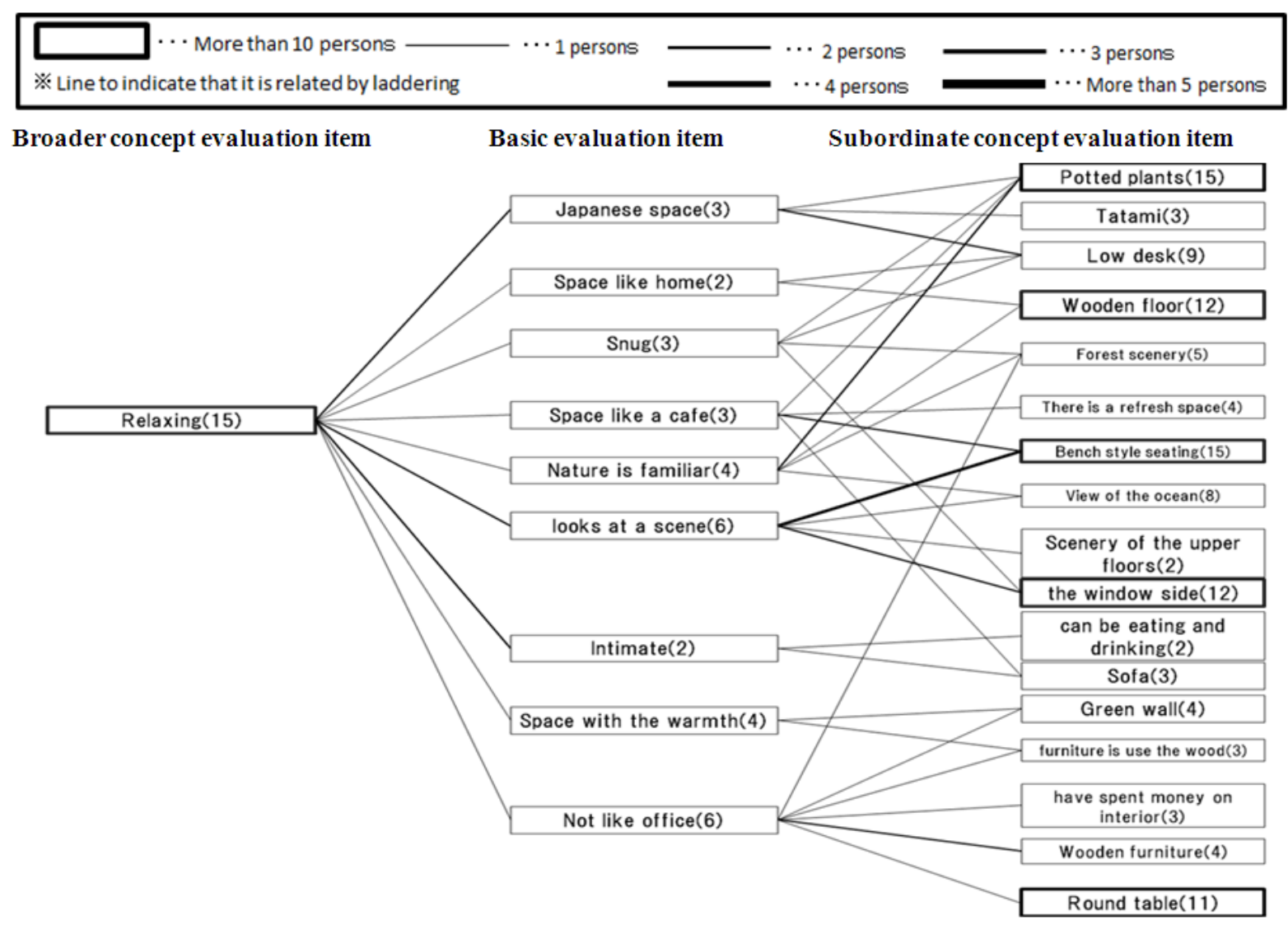

Fig. 9 Evaluation items on "relaxing".

contrast, our study adopted the conventional evaluation grid method based on awareness in the process of configuring a space using a CG-based miniature garden approach as the original construct. We then compiled evaluation structure diagrams using the miniature garden CG evaluation grid method. In order that the participants themselves can create office spaces using component parts prepared in advance, specific methods and techniques are derived that satisfy the basic concept of environmental evaluation items using the ladder down interview approach. For example, in addition to the visual environment, these include interpersonal relations within the internal space-free addressing scheme, no hierarchical relationship, people in a diagonal direction, people in close proximity, round table, etc.-a mobile work style system that can be moved around within the environment, evaluation items for parts used in creating office spaces that are not prepared in advance, and so on. Regarding the number of evaluation items derived, we would also note that the Inui approach based on photographs [10] derived only 11 broader concept evaluation items, while our CG-based approach derived 25 broader concept evaluation items, and thus results in more fine-grained results. This is because, in our study, the subjects themselves are in charge of operating the CAD software, so they themselves must face the challenge of creating office spaces based on their own subjective whims. Taking the evaluation item relaxation as an example, we find that several basic evaluation and subordinate concept evaluation items are derived that are correlated with relaxation (Fig. 10). Relaxating correlated with nature is familiar, and both are strongly correlated with plantings. And if we look for correlations based on planting, we find that this item correlated with nature is familiar, which is correlated with still other evaluation items: relaxating, refreshing, fatigue, and 

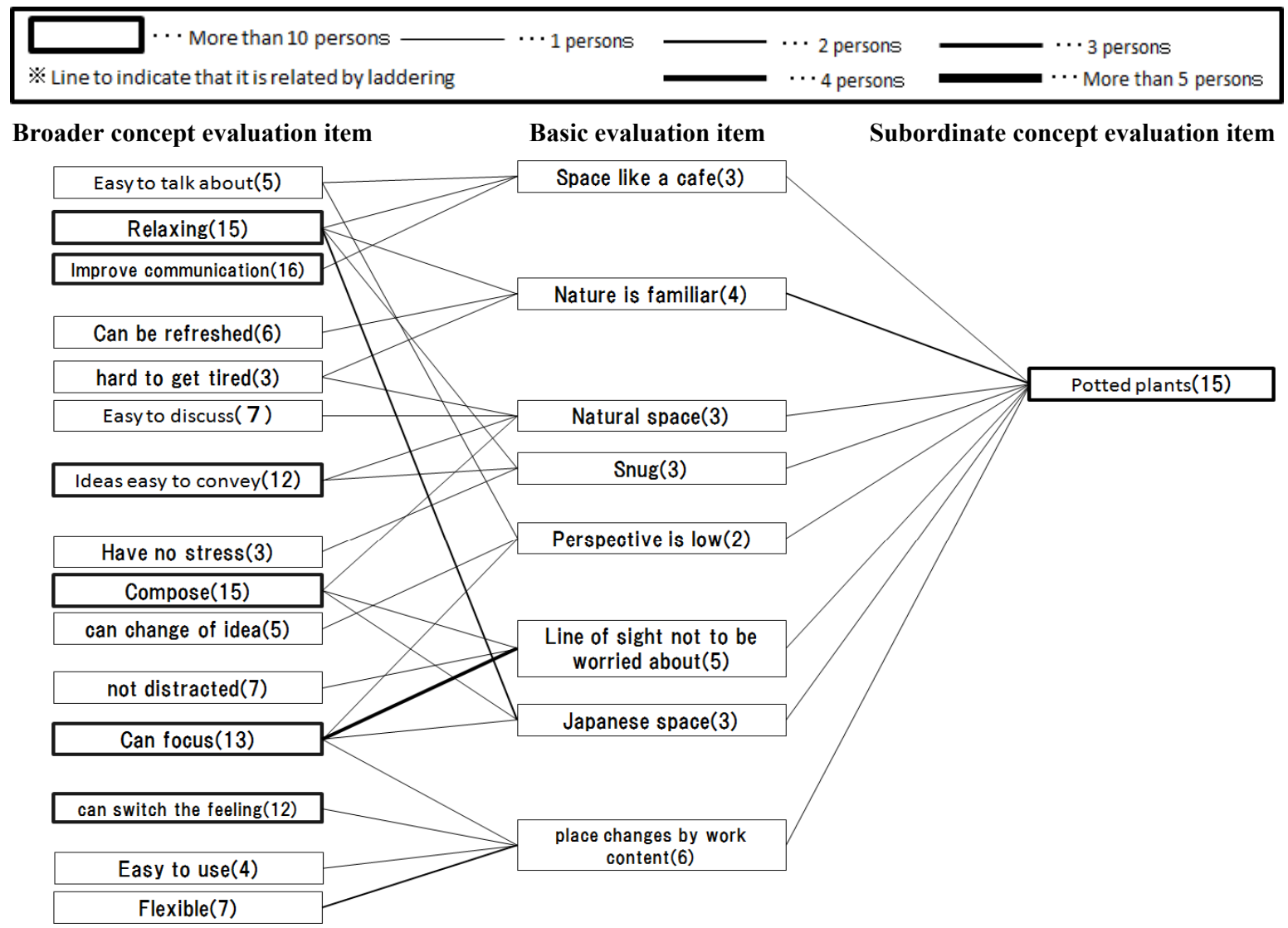

Fig. 10 Evaluation items on "There is a planting".

others (Fig. 11). After the experiment, the participants filled out a questionnaire (Fig. 11), and were asked if they could "envision themselves in the office space designed?" The most common response given by 11 of the participants was "Yes, I can somewhat envision myself in the space". Those 11 coupled with the more positive response "Yes, I can definitely envision myself in the space", brought the number up to more than 15 , or more than half the participants. Considering that none of the participants responded "No, I can not envision myself in the space", it is apparent that using the miniature garden approach to design office spaces does indeed enable the participants subjectively imagine what it is like in the office spaces they design. This suggests that the CAD-based miniature garden approach is very useful to creating a wide range of subjective fine-grained evaluations structures. Regarding parts prepared in advance, the questionnaire asked the participants if they would like to see more or fewer types of furniture. Most responded that they prefer "far fewer" types of furniture, while none of the respondents asked for "much more" or "somewhat more" types of furniture. This is why one sees far more furniture-related items in the evaluation structure diagram - round table, an oval-shaped desk, sofa, change the color of furniture, wooden furniture, etc. - than evaluation items about floors, walls and other materials. We believe that this feeling that there is not enough furniture to configure the space itself represents an awareness opportunity on the part of the subjects regarding the office environment.

\subsection{Considerations: Created Office Space}

Here we consider the intent of the subjects from correlations between the component parts they selected in creating their miniature gardens and evaluation structures. Nine of the 30 participants 
About CAD

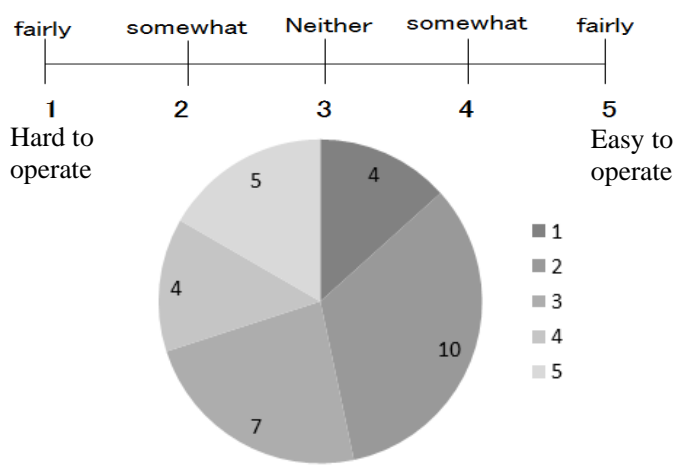

The actual space

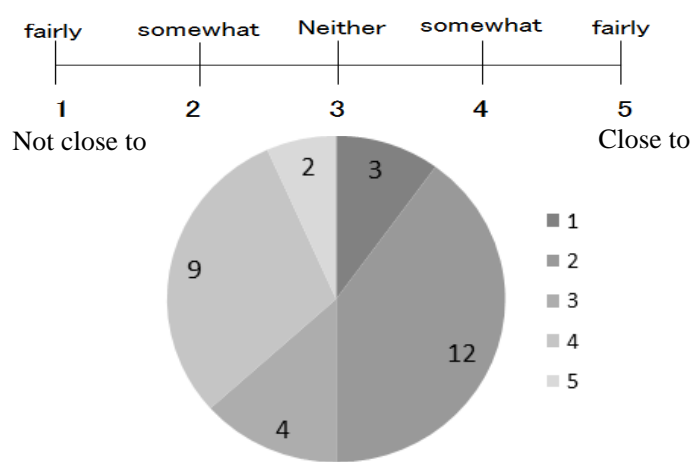

How you have their space

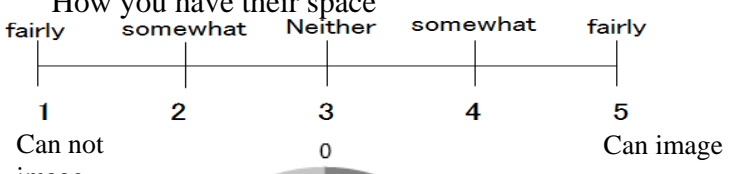

image

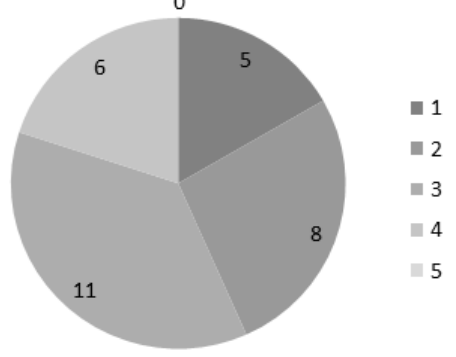

Type of floor

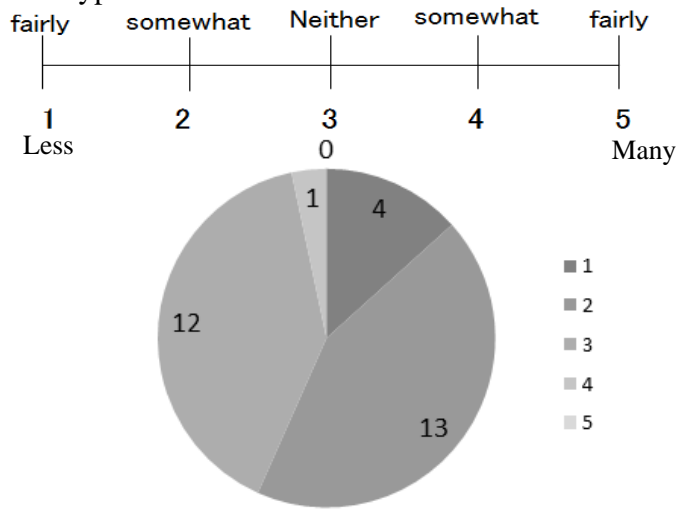

\section{About CAD}

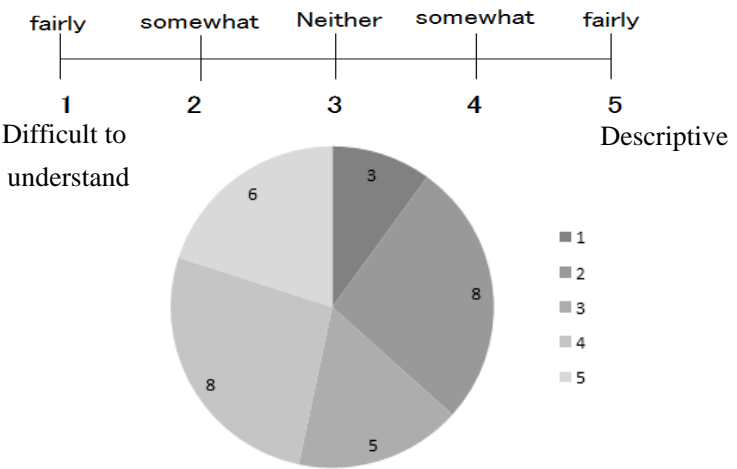

Sense of distance of space

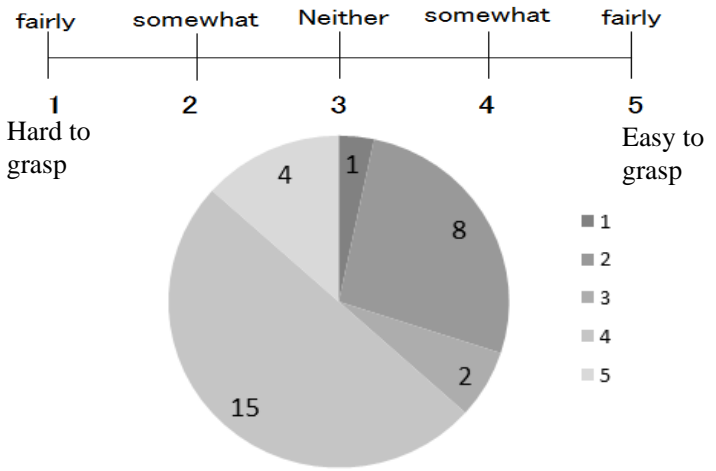

Type of wall

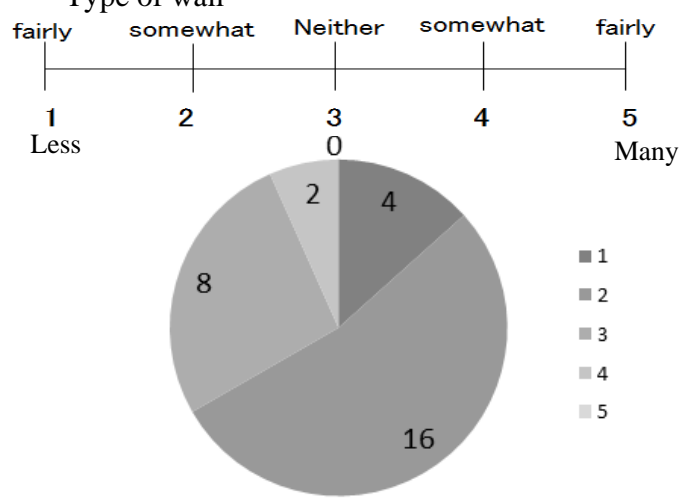

Type of furniture

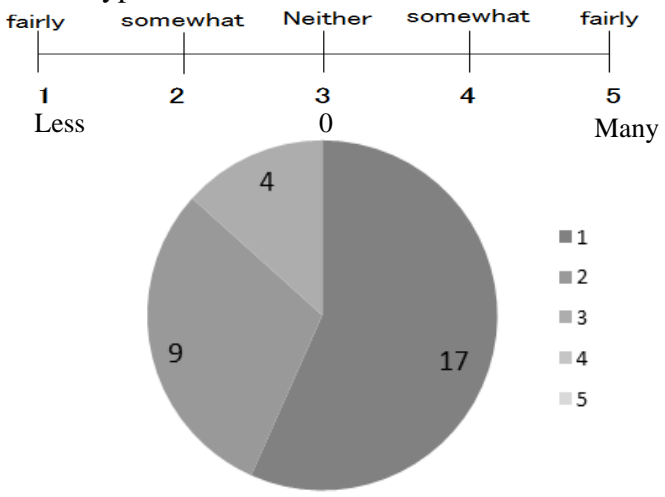



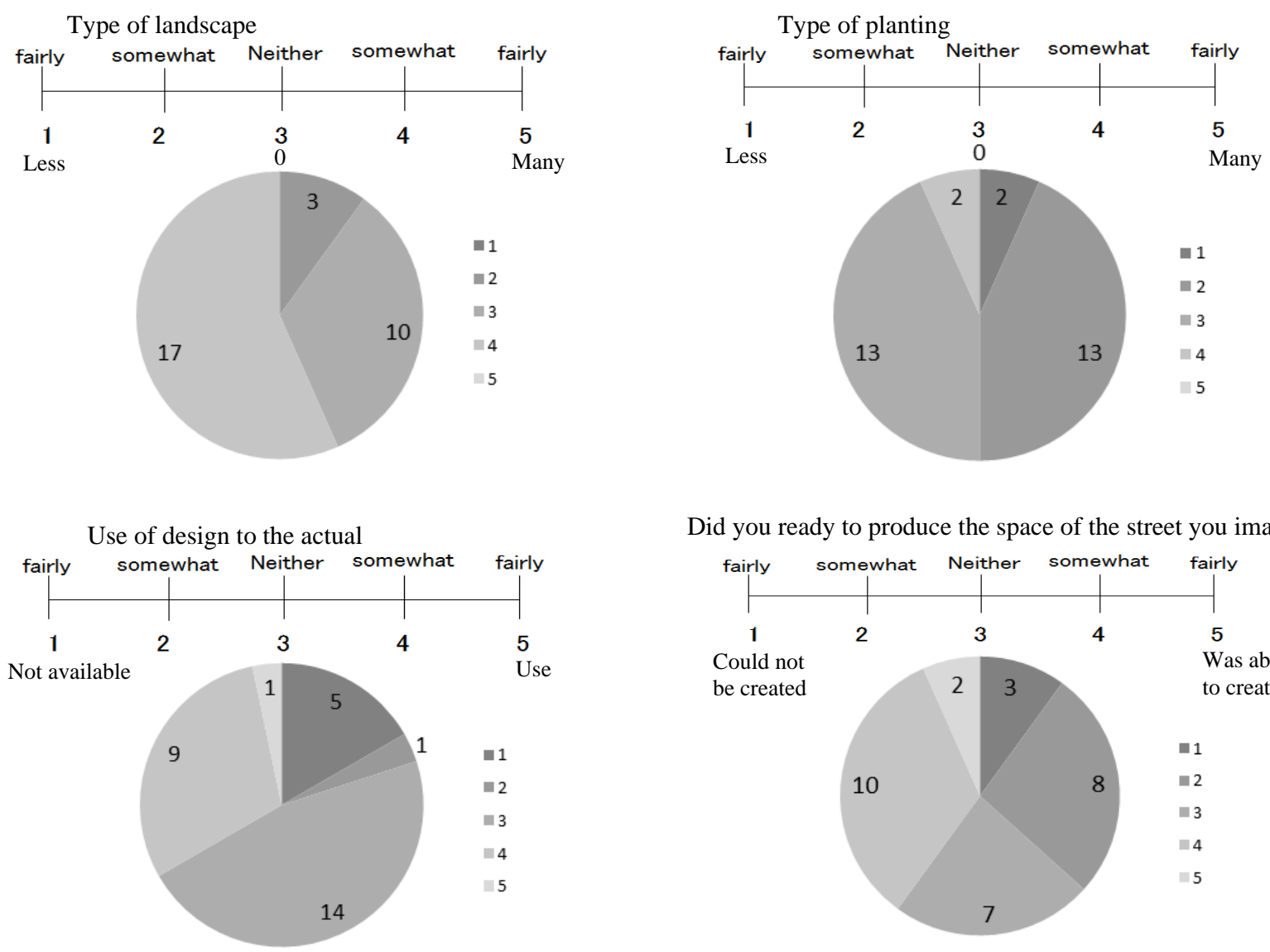

Did you ready to produce the space of the street you image

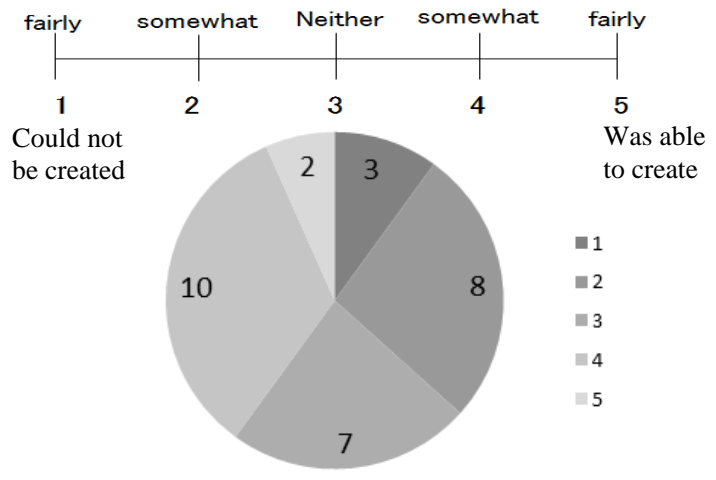

Fig. 11 Questionnaire result.

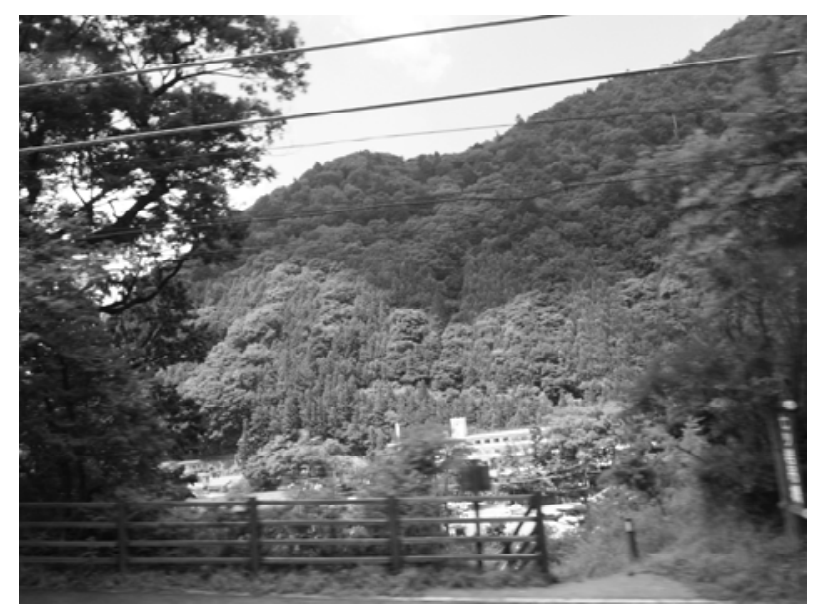

Fig. 12 Mountain views.

chose mountain view (Fig. 12) as their preferred office view. We can observe a correlation among the evaluation items natural space, nature is familiar, not office-like, and snug in the evaluation structure diagram. Moreover, these items are correlated with relaxing, conducive to ideas, and refreshing. Because

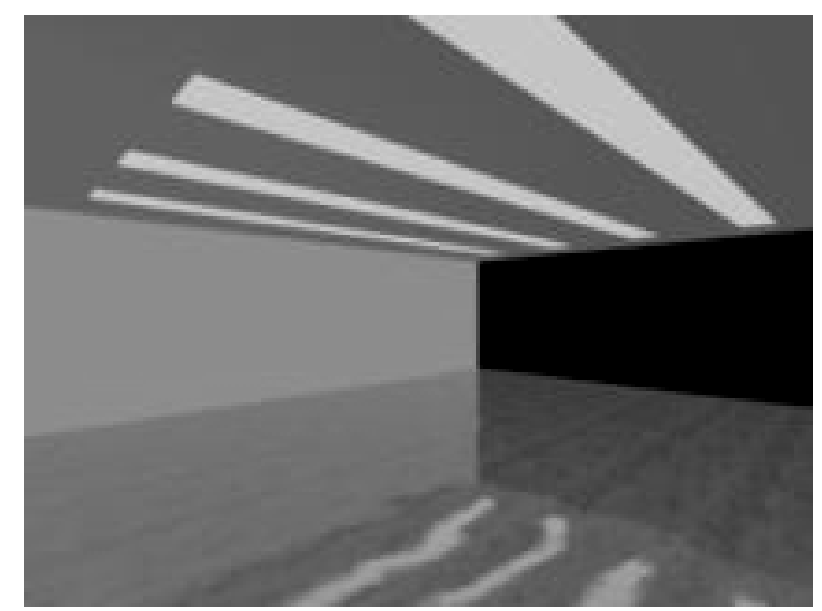

Fig. 13 (Bright colors) Flooring.

the participants all want a space where they can relax, naturally they tend to choose mountain view as the optimum scenery where they can relax in non-office-like setting that feels close to nature.

Thirteen out of 30 of the office worker participants choose bright-colored flooring (Fig. 13). This choice 
is correlated with nature is familiar, natural space and home-like space, which are all correlated with relaxing and comfortable.

It will be apparent from these results that, even when the intensions and types of materials chosen by the participants are the same, the evaluation items leading to those choices and the reasoning behind the choices are often different. Because the evaluation structure we advocate here is so detailed and fine-grained, we are able to apprehend even minority views.

\section{Conclusions and Future Prospects}

Let us summarize by highlighting the key findings of the study:

(1) Charged with designing office spaces to stimulate intellectual activity, office workers tended to emphasize interior comfort with evaluation items such as "relaxation", "settled”, “counter-type desks" and "plantings", and seek environments that are conducive easy conversation and communication;

(2) It was found that office workers have a rich vocabulary for describing office environments, and basic evaluation items are wide-ranging that a coherent unified set of items could not be derived;

(3) The miniature garden approach for designing office spaces enables subjects to subjectively reflect upon how the internal space will appear. Especially, considering the immersive quality of this technique, we believe the miniature garden method is very effective for conveying a clear understanding of office spaces to users;

(4) Because the miniature garden scheme only provides a limited and insufficient number of component parts, participants find themselves longing for greater selection, thinking long and hard and envisioning the parts they need, and this makes it possible to extract even more evaluation items.

The questionnaire results revealed that, using the miniature garden method, the wall and floor colors prepared in advance were defective. This likely resulted in a certain amount of bias in the designs, so we have to give more consideration to the selection of parts.

The experiment presented here was conceived with individual subjects in mind. However, office spaces are not just used by individuals but by groups, so they should be examined from a group perspective. Over the next year, we plan to conduct another experiment tailored for groups that will give us a chance to study more refined evaluation items and realistic procedures.

\section{References}

[1] National Population and Social Security Research: Population Projections for Japan, Table 1-1 Total Population, Age Structure Factor and Three Classification Population by Age: Birth Medium Variant, 2008.

[2] Workplace and Intellectual Activity, Eds. Institute for Building Environment and Energy Conservation, Cooperation, Intellectual Productivity Research Consortium/Intellectual Productivity Committee, 2010, pp. 9-11.

[3] M. Haneda, N. Nishihara, S. Tanabe, Subjective Experiment for the effect of road tranffic noise on productivity, Journal of Environmental Engineering 73 (625) (2008) 355-362.

[4] M. Nishikawa, N. Nishihara, S. Tanabe, Subjective experiments on productivity under $800 \mathrm{~lx}$ and $3 \mathrm{~lx}$ lighting conditions, Journal of Environmental Engineering 73 (625) (2008) 349-353.

[5] M. Nishikawa, N. Nishihara, S. Tanabe, The effect of moderately hot environment on performance and fatigue evaluated by subjective experiment of long time exposure, Journal of Environmental Engineering 74 (638) (2009) 525-530.

[6] M. Haneda, N. Nishihara, S. Tanabe, Subjective experiment for the effect of thermal environment and ventilation rate on productivity, Journal of Environmental Engineering 74 (638) (2009) 507-515.

[7] M. Haneda, N. Nishihara, G. Kawaguchi, S. Tanabe, Profuctivity in office with elevated preset temperature in summer, Journal of Environmental Engineering 74 (646) (2009) 1329-1337.

[8] M. Haneda, N. Nishihara, S. Nakamura, S. Uchida, S. Tanabe, A field measurement of thermal environment in cool biz office and the evaluation on productivity by a questionnaire survey, Journal of Environmental Engineering 74 (637) (2006) 491-493. 
[9] Third Edition Compact Design Data Aggregation, Architectural Institute of Japan Reviews, 2005, pp. 60-62.

[10] M. Inui, Y. Nakamura, T. Kubota, G. Maruyama, J. Lee,
The evaluation of office environment, Journal of Architecture, Planning and Environmental Engineering 399 (1989) 29-36. 